\title{
Technology-Facilitated Violence and Abuse: International Perspectives and Experiences
}

\author{
Jane Bailey, Nicola Henry, and Asher Flynn
}

\begin{abstract}
While digital technologies have led to many important social and cultural advances worldwide, they also facilitate the perpetration of violence, abuse and harassment, known as technology-facilitated violence and abuse (TFVA). TFVA includes a spectrum of behaviors perpetrated online, offline, and through a range of technologies, including artificial intelligence, livestreaming, GPS tracking, and social media. This chapter provides an overview of TFVA, including a brief snapshot of existing quantitative and qualitative research relating to various forms of TFVA. It then discusses the aims and contributions of this book as a whole, before outlining five overarching themes arising from the contributions. The chapter concludes by mapping out the structure of the book.
\end{abstract}

Keywords: Technology-facilitated; violence and abuse; digital crime; intersectionality; violence; systemic discrimination and abuse

\section{Introduction}

Digital technologies have led to many important social and cultural changes worldwide, but they are also implicated in the facilitation of abusive behaviors. Technology-facilitated violence and abuse (TFVA) is an umbrella term used to describe the use of digital technologies to perpetrate interpersonal harassment, abuse, and violence, such as sexual violence (e.g., Powell \& Henry, 2017), domestic and family violence (e.g., Douglas, Harris, \& Dragiewicz, 2019;

The Emerald International Handbook of Technology-Facilitated Violence and Abuse, 1-17

Copyright () 2021 Jane Bailey, Nicola Henry, and Asher Flynn

Published by Emerald Publishing Limited. This chapter is published under the Creative

Commons Attribution (CC BY 4.0) licence. Anyone may reproduce, distribute, translate and create derivative works of these chapters (for both commercial and non-commercial purposes), subject to full attribution to the original publication and authors. The full terms of this licence may be seen at http://creativecommons.org/licences/by/4.0/legalcode.

doi:10.1108/978-1-83982-848-520211001 
Fraser, Olsen, Lee, Southworth, \& Tucker, 2010; Woodlock, 2017), prejudicebased hatred (e.g., Barnett, 2007; Citron, 2014; Perry \& Olsson, 2009), and online othering (e.g., Lumsden \& Harmer, 2019).

There are numerous examples of TFVA. These include (but are not limited to) technology-facilitated sexual assault (the use of digital devices or apps to facilitate in-person sexual assault); image-based sexual abuse (the nonconsensual taking, sharing, or threats to share intimate images); cyberstalking (surveillance, monitoring, repeated contact, and impersonation); unwelcome requests and sexual solicitation; image-based harassment (the sending of unwanted and unsolicited explicit images); hate speech; threats of rape and violence; restricting access to and use of technology for purposes of isolation and coercion; exposure to violent and abusive imagery (whether sexual or nonsexual); the creation, distribution, and possession of child sexual exploitation materials; cyberbullying; and the nonconsensual disclosure of personal information, also known as "doxxing." TFVA is carried out through text, images, and unwanted digitally-enabled or enhanced surveillance and monitoring, using a variety of devices and platforms from basic digital tools, such as texting, email, and social media, to more advanced technologies such as artificial intelligence (AI) (Flynn, 2019; Henry, Powell, \& Flynn, 2018), GPS tracking (Wong, 2019), and drones (Thomasen, 2018).

TFVA arises in both public and private contexts across a spectrum of human relationships between strangers, acquaintances, friends, family members, and intimate partners (Citron, 2014). While a broad spectrum of people have experienced TFVA across different categories of age, sex, race, ethnicity, ability, sexuality, or socioeconomic status, TFVA is not simply a collection of random acts of hostility and animosity. It is a product of existing intersecting layers of structural and systemic inequalities (Southern \& Harmer, 2019), such as misogyny (Henry, Flynn, \& Powell, 2020), homophobia (Green, 2019), transphobia (Colliver, Coyle, \& Silvestri, 2019), racism (Kerrigan, 2019), colonialism (Carlson, 2019), and ableism (Hall, 2019), with some forms disproportionately affecting children and young people (Powell \& Henry, 2019; Quayle \& Koukopoulos, 2018). Further, in the digital environment, corporate structuring and monitoring practices for the purposes of maximizing profit contribute to and shape TFVA, its proliferation, and its impacts (Dragiewicz et al., 2018).

This introduction provides an overview of existing quantitative and qualitative research relating to various forms of TFVA. It then discusses the aims and contributions of this Handbook, highlighting the breadth of the research included, before proceeding to focus on five overarching themes arising from these collected works. Finally, it maps out the sections within the book, each of which is preceded in the Handbook by its own introductory remarks.

\section{Existing Research on TFVA}

\section{Quantitative Studies}

While its presence and impacts span the globe, much of the existing published quantitative and qualitative research on TFVA is dominated by industrialized nations in the Global-North, such as Australia, the United States, and the United Kingdom. Some quantitative (survey-based) research has examined TFVA across a 
range of behaviors (e.g., Australia Institute, 2019; Pew Research Center, 2014; Powell \& Henry, 2019). Others have focused on individual behaviors, for example, image-based sexual abuse (e.g., Citron, 2014; Lenhart, Ybarra, \& Price-Feeney, 2016a; Henry et al., 2020; OeSC, 2017; Powell, Henry, \& Flynn, 2018; Powell, Henry, Flynn, \& Scott, 2019; Powell, Scott, Henry, \& Flynn, 2020; Ruvalcaba \& Eaton, 2019); digital dating abuse (e.g., Borrajo, Gámez-Guadix, Pereda, \& Calvete 2015; Burke, Wallen, Vail-Smith, \& Knox, 2011; Marganski \& Melander, 2018; Martinez-Pecino \& Durán, 2019; Ybarra, Price-Feeney, Lenhart, \& Zickuhr, 2017); hate speech (e.g., OeSC, 2020); image-based harassment (e.g., Oswald, Lopes, Skoda, Hesse \& Pederson, 2020); trolling (e.g., Akhtar \& Morrison, 2019); online sexual harassment (e.g., Baumgartner, Valkenburg, \& Peter, 2010; Douglass, Wright, Davis, \& Lim, 2018; Powell \& Henry, 2017); and cyberbullying (especially among youth - for a scoping review, see Brochado, Soares, \& Fraga, 2016). Little quantitative research has investigated sexual assault victimization via online dating sites/apps or online rape threats (Powell \& Henry, 2017; Rowse, Bolt, \& Gaya, 2020), although a considerable amount of quantitative research has focused on online child sexual exploitation (e.g., Karayianni, Fanti, Diakidoy, Hadjicharamlambous, \& Katsimicha, 2017).

With the exception of studies on digital dating abuse (e.g., Borrajo et al., 2015; Burke et al., 2011; Marganski \& Melander, 2018; Martinez-Pecino \& Durán, 2019; Ybarra et al., 2017), there is very little prevalence data on TFVA in the context of domestic and family violence (Messing, Bagwell-Gray, Brown, Kappas, \& Durfee, 2020; Woodlock, 2017). Relatedly, little is known about the nexus or co-occurrence of TFVA with "in-person" experiences of sexual and domestic violence (Marganski \& Melander, 2018) - also known as "polyvictimization" (Finkelhor, Ormrod, Turner, \& Hamby, 2005). Studies on cyberbullying show that victim-survivors are more likely to be also victims of offline bullying, such as abuse in the school yard (e.g., Hinduja \& Patchin, 2008).

\section{Qualitative Studies}

A variety of qualitative studies have been conducted with "targets" (or victimsurvivors) and frontline workers who support them in relation to cyberstalking (e.g., Dimond, Fiesler, \& Bruckman, 2011; Weathers \& Hopson, 2015); technologyfacilitated domestic violence (Douglas et al., 2019; Dragiewicz et al., 2019; George \& Harris, 2014; Harris \& Woodlock, 2019; OeSC, 2019a; Woodlock, 2017); imagebased sexual abuse (Amudsen, 2019; Bates, 2017; Henry, Flynn, \& Powell, 2018; Henry et al., 2020; McGlynn et al., 2019, 2020; OeSC, 2017); image-based sexual harassment (Mandau, 2020); online sexual harassment; technology-facilitated sexual assault (Gillett, 2019); online hate (Lewis, Rowe, \& Wiper, 2019; Smith, 2019); online child sexual exploitation (e.g., Gerwitz-Meydan, Walsh, Wolak, \& Finkelhor, 2018; for an overview of studies see; DeMarco, Sharrock, Crowther, \& Barnard, 2018); cyberbullying (especially in relation to children and youth - for an overview of studies see Dennehy et al., 2020); and TFVA more broadly (Henry \& Powell, 2015; OeSC, 2019a, b; Powell \& Henry, 2017). More research focusing on the experiences of Indigenous peoples; racial minorities; people with disabilities [but see: Alhaboby, al-Khateeb, Barnes, and Short (2016); Alhaboby, Barnes, Evans, and Short (2019)]; 
sex workers; lesbian, gay, bisexual, transgender, queer, and intersex (LGBTQI+) people; as well as those living in rural, regional, and remote areas is needed. Quantitative studies have shown that these groups (especially women within these groups) are more likely to experience TFVA and/or to experience more adverse impacts (e.g., Henry et al., 2020; Powell et al., 2019, 2020; OeSC, 2017, 2019a, b; Douglas et al., 2018; Lenhart, Ybarra, Zickuhr, \& Price-Feeney, 2016b; Powell \& Henry, 2019; Ybarra et al., 2017).

There have been relatively few qualitative studies of TFVA perpetrators and bystanders, although there are a number focused on offenders in the contexts of online child sexual exploitation and abuse (e.g., DeMarco et al., 2018), image-based sexual abuse against adults (e.g., Hall \& Hearn, 2017; Henry \& Flynn, 2019; OeSC, 2019c; Uhl et al., 2018); and online hate speech (e.g., Jane, 2014). Additionally, a number of qualitative studies have focused on perpetrator behaviors by examining content on online platforms, such as 4chan (Green, 2019), Reddit (Lumsden, 2019), Twitter (Megarry, 2014; Southern \& Harmer, 2019), YouTube (Colliver et al., 2019), and Facebook (Scrivens \& Amarasingam, 2020).

\section{Research on Responses to TFVA}

Often the empirical literature on TFVA also includes recommendations as to how best to respond to TFVA (see, e.g., Bailey, 2015; Harris, 2020; Henry, Flynn, \& Powell, 2019; Powell et al., 2020). There is also, however, a significant literature focused primarily on proposing and/or analyzing the efficacy of one or more responses, including legal (criminal, civil, human rights, and regulatory), technological, and educational approaches, as well as improved support for TFVA targets and self-help initiatives undertaken by targets themselves.

In some cases, the analyses address TFVA generally (see, e.g., Bailey \& Mathen, 2019; Dunn, Lalonde, \& Bailey, 2017; Sheikh, 2018). In other cases, they focus on responses to specific forms of TFVA, including image-based sexual abuse [see, e.g., Citron \& Franks, 2014 (focusing on criminal law); Dodge, 2019 (focusing on criminal law); Henry et al., 2020 (focusing on a range of legal and nonlegal responses); Powell \& Henry, 2017 (focusing on digital citizenship)]; online hate speech [see, e.g., Bailey, 2010 (focusing on human rights-based legal responses); Citron, 2014 (focusing on a range of responses)]; online harassment and trolling [see, e.g., Bailey, 2017 (focusing on education policy); Citron, 2014; Pavan, 2017 (focusing on intermediary responsibility)]; cyberbullying [see, e.g., Hinduja, 2018 (focusing on building resilience)]; technology-facilitated intimate partner violence [see, e.g., Al-Alosi, 2020 (both considering technological responses); Harris, 2020; Tanczer, Lopez Neira, Parkin, Patel, \& Danezis, 2018 (considering, among other things, improved security legislation)]; online child sexual exploitation [see, e.g., Bailey, 2007 (considering criminal law responses); Salter, 2018 (considering, among other things, therapeutic and legal responses)]; online sexual harassment [see, e.g., Jane, 2017; Vitis \& Gilmour, 2017 (both focusing self-help/grassroots responses)]; and abusive and offensive online content [see, e.g., Bailey, 2018; Cheer, 2018; Schweppe, 2018 (all focusing primarily on criminal law responses)]. 


\section{This Handbook}

We imagined this collection as one that would contribute to the existing landscape in part by breaking away from geographic, sectoral, and disciplinary silos. To achieve this, we have brought together the work of a diverse range of contributors from 13 countries (Australia, Brasil, Canada, Eswatini, Finland, Hong Kong, Malawi, Malta, New Zealand, Nigeria, Scotland, the United Kingdom, and the United States) and seven different sectors (academia, ICT, nonprofit, consulting, policy, regulatory, and legal practice). Our academic contributions come from scholars in 11 different fields (communications/media studies; law; sociology; health; education; political studies; justice/criminology; behavioral studies; social, global, and cultural studies; digital ethics; and science and engineering), some of whom collaborated with contributors from different areas in the nonprofit sector (women's rights/gender equality, public health, development, privacy rights, and domestic violence). Our contributors report on research drawing on the lived experiences of TFVA targets in places around the globe from a wide range of social locations affected by categories such as gender, gender identity, age, sexual identity, race, and indigeneity, as well as from the on-the-ground advocates and community organizations that support them. They also present insights from academics and policy organizations actively engaged in developing meaningful responses for preventing and/or remedying the harms they inflict, as well as firsthand perspectives from TFVA perpetrators.

Our aim in bringing together this international, intersectoral, intersectional, and interdisciplinary group of contributors, whose work covers a wide spectrum of forms of TFVA, is to produce synergies that reinvigorate discussions of TFVA, encouraging opportunities for future collaboration, as well as insights from one area that could be applied to others. We also hope that in showcasing a range of legal, empirical, and theoretical research focused on the targets, support services, and perpetrators of TFVA, across a diverse range of social locations, as well as multiple strategies for addressing TFVA, this collection can contribute toward nuanced understandings of this complex phenomenon that can open up opportunities for developing meaningful multifaceted responses grounded in recognition of TFVA as both a product and producer of intersecting systems of power.

\section{Research Contributions of this Handbook}

This Handbook's empirical contributions include qualitative analyses of:

(1) Interviews and/or focus groups with:

- Men who have sex with men, and their understandings of "rape culture" on Grindr (Dietzel);

- Brasilian and Australian advocates working on technology-facilitated intimate partner abuse among youth (Lopes Gomes Pinto Ferreira);

- Canadian women who have experienced online abuse (Gosse); 
- Women in remote, regional, and rural areas of Australia who have experienced digital coercive control (Harris \& Woodlock, 2018);

- Australian women who have experienced online lateral violence from other women (Jane);

- New Zealand young heterosexual adults on their experiences of pleasure and harm relating to online pornography (Keene);

- Australian domestic violence practitioners on the experiences of their culturally and linguistically diverse women clients (Louie);

- Canadian sexual violence frontline professionals on their clients' experiences of nonconsensual disclosure of intimate images (Marques);

- US college students' understandings of the impacts of technologically shared images of racist police brutality (Novich \& Zduniak);

- Singaporean frontline domestic violence, sexual violence, and LGBTQI+ support workers and the experiences of their clients (Vitis);

(2) Online content including:

- Counter-hegemonic responses to gendered violence on Twitter (Broadbent \& Thompson);

- Transphobic comments on YouTube (Colliver);

- Digital platform policies to identify whether and how they address imagebased sexual abuse (Henry \& Witt);

- Discriminatory discussion threads posted on a Finnish discussion forum (Vaahensalo);

- Self-help efforts to address online child sexual exploitation (Salter \& Hanson); and

(3) Existing research on:

- Doxxing (Anderson \& Wood);

- Polyvictimization and TFVA (DeKeseredy, Lory, \& Stoneberg); and

- TFVA against members of Indigenous communities (Bailey \& Shayan; Carlson \& Frazer).

This Handbook's empirical contributions also include quantitative analyses of:

(1) Young people's experiences of TFVA in sub-Saharan Africa (Makinde, Olamijuwon, Ichegbo, \& Ilesanmi);

(2) Adult perpetrators of TFVA in New Zealand (Pacheco \& Melhuish); and

(3) Gay and bisexual men's sharing and privacy-protection practices when using queer dating apps (Waldman).

Finally, this Handbook contributes to the literature relating to the spectrum of responses to TFVA, through analyses of:

(1) Theoretical and legal understandings of "violence" and the place of TFVA within them (Dunn);

(2) Legal responses to image and text-based abuse in the United Kingdom (Barker \& Jurasz); 
(3) International law instruments applicable to TFVA, particularly genderbased TFVA (Coombs);

(4) International and Arab region legal responses to gender-based TFVA (Al Nasrawi);

(5) Legal responses to image-based sexual abuse in Malawi and Scotland (Chisala-Templehoff \& Stevenson);

(6) Judicial approaches to prosecution of (ex) intimate partners for nonconsensual distribution of intimate images in Canadian criminal law proceedings (Aikenhead);

(7) Legal approaches to privacy in the context of TFVA (Thomasen \& Dunn);

(8) Legal approaches to doxxing in Hong Kong (Cheung);

(9) Benefits and limitations of responding to TFVA through statutory agencies (Hrick);

(10) Technology-based responses to TFVA (Marganski \& Melander; PenzeyMoog \& Slakoff; Slupska \& Tanczer);

(11) Community-based/self-help/collaborative responses to TFVA (Broadbent \& Thompson; Lytle, Hudson, \& Bratton; Bailey \& Liliefeldt); and

(12) Corporate responsibility for TFVA (Salter \& Hanson; Henry \& Witt).

\section{Five Key Insights from this Handbook}

While this collection yields a myriad of insights and possibilities for future engagement, below we highlight five overarching themes interwoven within this diverse group of contributions: (i) the importance of context; (ii) the need to define and redefine understandings of "violence"; (iii) the power of words and images; (iv) the need to think systemically; and (v) the need to employ a spectrum of legal responses that move beyond criminal law, as well as approaches beyond law altogether. Here we highlight aspects of each of these, leaving more detailed analyses of the content of each chapter for the introductions that precede each section of the collection.

\section{The Importance of Context}

The importance of taking context into account in order to better understand and respond to TFVA emerges from this collection in three main ways. The first relates to the critical role that contextuality plays in social science research focused on TFVA. For example, the chapters of Edgar Pacheco and Neil Melhuish, Olusean Makinde et al., and Lopes Gomes Pinto Ferreira, underscore the importance of supplementing quantitative findings with in-depth qualitative analyses in order to better understand and represent lived perspectives. These chapters raise questions about why those who perpetrate and experience behaviors often associated with TFVA fail to categorize them as forms of violence and abuse. There may be a variety of reasons to explain such quantitative findings. Perhaps survey respondents are uninformed or they are immersed in environments where violence is normalized. On the other hand, 
particular sorts of behavior (e.g., repeatedly texting someone during the day) could be part of otherwise harmless or even consensual practices. In these kinds of cases, supplemental qualitative research will often be a useful tool for better understanding the context in which listed behaviors are occurring, and concomitantly how to identify and meaningfully address those that are problematic. Further, as Bronwyn Carlson and Ryan Frazer point out, perspectives about "what counts" as a form of TFVA can be intimately interconnected with culture, thereby undermining the explanatory power of quantitative research based on standardized definitions with members of mainstream groups.

Second, context can and arguably should play a critical role in developing legal responses to TFVA. Anne Cheung's chapter, for example, illustrates the importance of sociopolitical context in differentiating legal responses to nonconsensually disclosing personal information about others online (doxxing) for the purposes of calling public authorities to account from doxxing for other motivations, such as sexual shaming and humiliation. Cheung's particular approach to doxxing in the Hong Kong context is consistent with Bree Anderson and Mark Wood's more general conclusion that doxxing should be understood as a typology of "interconnected motivations, expressions and experiences of harm." Seonaid StevensonMcCabe's and Sarai Chisala-Templehoff's chapter emphasizes the role that context plays in determining whether a legal solution from one jurisdiction is likely to be workable in another. Kristen Thomasen's and Suzie Dunn's chapter centers the role of equality considerations in the legal interpretation and application of privacy principles, especially in cases involving the nonconsensual disclosure of intimate images, a form of privacy violation with particular consequences for women and members of LGBTQI+ communities that arise primarily from preexisting prejudices such as misogyny, homophobia, and transphobia.

Third, the chapters by Elena Cama, Chris Dietzel, and Moira Aikenhead remind us of the impact of preexisting rape cultures on understandings of and responses to TFVA. Cama and Dietzel's chapters connect sexually violent forms of TFVA on dating apps with pervasive myths and stereotypes about sexuality and gender that serve to normalize and excuse sexual violence harms. Similarly, Aikenhead's analysis of so-called "revenge porn" cases prosecuted under Canada's criminal prohibition on the nondisclosure of intimate images reveals the way that rape culture myths around women's sexuality lead to blaming targets for their own victimization and consequently manifest themselves in fact and in law.

\section{Defining and Redefining "Violence"}

Several chapters in the collection underscore the importance of grappling with preexisting conceptions of "violence" in order to understand how nonphysical technology-facilitated behaviors can and should be understood as "violence." Suzie Dunn's chapter emphasizes the role that conceptualizing TFVA as violence can play in communicating its social unacceptability (even with respect to actions that do not rise to the level of being illegal). Chandel Gosse's chapter further illustrates the complex ways in which the "online/offline" dichotomy works to 
minimize TFVA and in burdening TFVA targets to prove that the harms are "real." The chapters by Walter DeKeseredy, Danielle Stoneberg, and Gabrielle Lory, Bridget Harris and Delanie Woodlock, and Laura Vitis further challenge this false dichotomy by demonstrating the ways that TFVA can both emanate from and bleed into harmful physical interactions.

\section{The Power of Words and Images}

In digitally networked environments, words and images have power, yet false dichotomies, such as online/offline and real/virtual, work to obscure the real impacts of TFVA. The chapters by Kim Barker and Olga Jurasz (on the need for a legal response to online verbal assaults), Bridget Harris and Delanie Woodlock (on remote, regional, and rural women's experiences of digital coercive control), Emma Jane (on lateral violence between women in online spaces), and Laura Vitis (on TFVA in the context of intimate partner violence) highlight in particular the power of words as tools for exerting control over others in ways that undermine targets' dignity, security, and sense of self-worth, as well as their willingness to participate in public life. Ben Colliver (on anti-trans online discourse) and Elina Vaahensalo (on online othering) graphically illustrate in their chapters how words and discursive strategies are used as tools for re/making an "other" in an attempt to justify (or at least rationalize) violence and abuse.

In terms of the power of images, Olga Marques' chapter emphasizes the dignity and privacy harms arising from intimate images being circulated without consent because the images become a form of permanent remembering that freezes understandings and perceptions of the target at a particular point in time, not of their choosing. The chapters of Samantha Keene, and Madeleine Novich and Alyssa Zduniak highlight the differential effects of, respectively, sexually violent mainstream pornographic images and images of acts of police brutality on online spectators from different social locations, again revealing the power of images to cause harm.

\section{Thinking Systemically: Corporations, the Role of the State, and Intersectionality}

This collection also highlights the need to rethink individuated understandings of TFVA in favor of analyses that seek to understand and address TFVA as both a product and reflection of corporate, state, and discriminatory social systems. As the chapters of Nicola Henry and Alice Witt, and Michael Salter and Elly Hanson demonstrate, TFVA is perpetuated not just by "bad individuals," but also by the systems and practices of the technology companies that structure and facilitate online interactions. Ari Waldman's chapter builds upon these insights, highlighting the ways in which these structures can undermine gay and bisexual male dating app users' self-help strategies for avoiding TFVA by compromising their ability to maintain greater privacy. Bronwyn Carlson and Ryan Frazer's chapter demonstrates the harm done by research approaches that attempt to 
"standardize" conceptions such as "cyberbullying," noting the ways in which such homogenization fails to account for the lived realities of Indigenous peoples, whose experiences are shaped both by cultural traditions, as well as by oftenintersecting "social forms of hate," including sexism, racism, homophobia, transphobia, and ableism. Jane Bailey and Sara Shayan's chapter reveals another outcome of taking a more systemic approach to TFVA. They highlight examples of both individual and state-based acts of TFVA targeting Indigenous peoples in Canada (with a particular focus on Indigenous women and girls), noting their intersecting colonialist, racist, and sexist underpinnings. Drawing on critical Indigenous scholarship, they argue Indigenous peoples are likely to have wellplaced mistrust in colonial state-based responses to TFVA given the state's own involvement in perpetrating such acts.

\section{Moving Beyond Law (Especially Criminal Law)}

While a number of contributors call for improved laws for combatting TFVA, the theme of moving beyond law arises in two key ways. First, contributions such as those of Pam Hrick (focusing on administrative and regulatory bodies) and those by Elizabeth Coombs and Sukaina Al-Nasrawi (focusing on international human rights norms), while maintaining a focus on legal responses, help us to understand the roles that legal responses other than criminal law can play. Second, several contributions move beyond law completely to focus on technology-driven prevention of and responses to TFVA. Moving beyond state-based legal responses to TFVA is likely to be of particular relevance and import to members of marginalized communities that are disparately likely to be targeted by many forms of state violence (Palmater, 2016). While the chapters of Lopes Gomes Pinto Ferreira, Yee Man Louie, and Bridget Harris and Delanie Woodlock, highlight the particularly useful role that technological responses may play in serving isolated and socially marginalized targets of IPV, Alison Marganski and Lisa Melander, Eva PenzeyMoog and Danielle Slakoff, and Julia Slupska and Leonie Tanczer grapple with challenges and solutions for grounding technological design in targets' lived experiences. Finally, Ella Broadbent and Chrissy Thompson (counter-hegemonic tweets), Robert Lytle, Tabrina Bratton, and Heather Hudson (bystander intervention), Salter and Hanson (online self-help initiatives of child sexual exploitation survivors), and Jane Bailey and Raine Liliefeldt (multisector collaboration) focus on individual and collective strategies that can, in some instances, be understood as self-help strategies for seeking justice when formal legal channels are undesired, unavailable, and/or ineffective.

As discussed further in our Conclusion, the significance of bringing together diverse insights, experiences, and strategies for addressing TFVA and the underlying systemic drivers that inform it, have taken on renewed significance since we began this collection in 2019. The COVID-19 pandemic and the global outpouring of protests against highly publicized instances of anti-Black and other forms of racist violence and discrimination serve to remind us of the complex entanglements between our common humanity and the deep social, political, 
economic, technological, and geographic divisions between us. We hope that the collection of ideas and analyses presented here will contribute toward imagining a way forward.

The collection begins with contributions examining TFVA across a spectrum of behaviors. It then focuses more specifically on text-based harms before proceeding to image-based harms. Next, it considers TFVA in the relational contexts of dating apps and IPV. The final two sections focus on responses, beginning with legal approaches and ending with responses that move beyond law.

\section{References}

Akhtar, S., \& Morrison, C. (2019). The prevalence and impact of online trolling of UK members of Parliament. Computers in Human Behavior, 99, 322-327. doi: 10.1016/j.chb.2019.05.015

Al-Alosi, H. (2020). Fighting fire with fire: Exploring the potential of technology to help victims combat intimate partner violence. Aggression and Violent Behavior, 52, 101376. doi:10.1016/j.avb.2020.101376

Alhaboby, Z. A., al-Khateeb, H. M., Barnes, J., \& Short, E. (2016). 'The language is disgusting and they refer to my disability': The cyberharassment of disabled people. Disability \& Society, 31, 1138-1143. doi:10.1080/09687599.2016.1235313

Alhaboby, Z., Barnes, J., Evans, H., \& Short, E. (2019). Cyber-victimization of people with chronic conditions and disabilities: A systematic review of scope and impact. Trauma, Violence, \& Abuse, 20(3), 398-415. doi:10.1177/1524838017717743

Amundsen, R. (2019). 'The price of admission': On notions of risk and responsibility in women's sexting practices. In K. Lumsden \& E. Harmer (Eds.), Online othering: Exploring digital violence and discrimination on the Web (pp. 145-164). Basingstoke: Palgrave Macmillan.

Australia Institute. (2019). Trolls and polls: The economic costs of online harassment and cyberhate. Retrieved from https://www.tai.org.au/content/trolls-and-polls-economic-costs-online-harassment-and-cyberhate

Bailey, J. (2007). Confronting collective harm: Technology's transformative impact on child pornography. University of New Brunswick Law Journal, 56, 65-102.

Bailey, J. (2010). Twenty years later Taylor still has it right: Section 13 of the CHRA's continuing contribution to equality. In S. McIntyre, \& S. Rodgers (Eds.), The Supreme Court of Canada and social justice: Commitment, retrenchment or retreat (pp. 1-39). Markham, ON: Supreme Court Law Review and LexisNexis Canada.

Bailey, J. (2015). A perfect storm: How the online environment, social norms and law constrain girls' online lives. In J. E. Bailey \& V. Steeves (Eds.), eGirls, eCitizens: Putting technology, theory and policy into dialogue with girls' and young women's voices (pp. 21-53). Ottawa, ON: University of Ottawa Press.

Bailey, J. (2017). From 'zero tolerance' to 'safe and accepting': Surveillance and equity implications of educational policy related to 'cyberbullying'. Education and Law Journal, 26, 146-162.

Bailey, J. (2018). Abusive and offensive speech online: An overview of Canadian legal responses focusing on the criminal law framework. London: UK Law Commission. Retrieved from https://s3-eu-west-2.amazonaws.com/lawcom-prod-storage-11jsxou 24uy7q/uploads/2018/11/Canada-J-Bailey.pdf 
Bailey, J., \& Mathen, C. (2019). Technology-facilitated violence against women and girls: Assessing the Canadian criminal law response. Canadian Bar Review, 97(3), 664.

Barnett, B. (2007). Untangling the web of hate: Are online hate sites deserving of First Amendment protection?. New York, NY: Cambria Press.

Bates, S. (2017). Revenge porn and mental health: A qualitative analysis of the mental health effects of revenge porn on female survivors. Feminist Criminology, 12(1), $22-42$.

Baumgartner, S. E., Valkenburg, P. M., \& Peter, J. (2010). Unwanted online sexual solicitation and risky sexual online behavior across the lifespan. Journal of Applied Developmental Psychology, 31(6), 439-447.

Borrajo, E., Gámez-Guadix, M., Pereda, N., \& Calvete, E. (2015). The development and validation of the cyber dating abuse questionnaire among young couples. Computers in Human Behavior, 48, 358-365.

Brochado, S., Soares, S., \& Fraga, S. (2016). A scoping review of studies on cyberbullying prevalence among adolescents. Trauma, Violence, \& Abuse, 18(5), 523-531. doi:10.1177/1524838016641668

Burke, S. C., Wallen, M., Vail-Smith, K., \& Knox, D. (2011). Using technology to control intimate partners: An exploratory study of college undergraduates. Computers in Human Behavior, 27(3), 1162-1167.

Carlson, B. (2019). Disrupting the master narrative: Indigenous people and tweeting colonial history [online]. Griffith Review, 64, 224-234. Retrieved from https:// search.informit.com.au/documentSummary; $\mathrm{dn}=341995259289589$;res=IELAPA$>$ ISSN:1839-2954. [cited 13 June 20].

Cheer, U. (2018). Abusive and offensive communications: The criminal law of New Zealand. London: UK Law Commission. Retrieved from https://s3-eu-west2.amazonaws.com/lawcom-prod-storage-11jsxou24uy7q/uploads/2018/11/NewZealand-U-Cheer.pdf

Citron, D. K. (2014). Hate crimes in cyberspace. Boston, MA: Harvard University Press.

Citron, D., \& Franks, M. A. (2014). Criminalizing revenge porn. Wake Forest Law Review, 49, 345-392.

Colliver, B., Coyle, A., \& Silvestri, M. (2019). The 'online othering' of transgender people in relation to 'gender neutral toilets'. In K. Lumsden \& E. Harmer (Eds.), Online othering: Exploring digital violence and discrimination on the Web (pp. 215-238). Cham: Palgrave Macmillan.

DeMarco, J., Sharrock, S., Crowther, T., \& Barnard, M. (2018). Behaviour and characteristics of perpetrators of online-facilitated child sexual abuse and exploitation: A rapid evidence assessment. Prepared for independent inquiry into child sexual abuse. London: NatCen Social Research.

Dennehy, R., Meaney, S., Walsh, K. A., Sinnott, C., Cronin, M., \& Arensman, E. (2020). Young people's conceptualizations of the nature of cyberbullying: A systematic review and synthesis of qualitative research. Aggression and Violent Behavior, 51, 101379. doi:10.1016/j.avb.2020.101379

Dimond, J., Fiesler, C., \& Bruckman, A. (2011). Domestic violence and information communication technologies. Interacting with Computers, 23(5), 413-421.

Dodge, A. (2019). Nudes are forever: Judicial interpretations of digital technology's impact on "revenge porn." Canadian Journal of Law and Society, 34(1), 121-143. 
Douglas, H., Harris, B., \& Dragiewicz, M. (2019). Technology-facilitated domestic and family violence: Women's experiences. British Journal of Criminology, 59(3), 551-570.

Douglass, C. H., Wright, C. J. C., Davis, A. C., \& Lim, M. S. C. (2018). Correlates of in-person and technology-facilitated sexual harassment from an online survey among young Australians. Sexual Health, 15(4), 361-365.

Dragiewicz, M., Burgess, J., Matamoros-Fernández, A., Salter, M., Suzor, N. P., Woodlock, D., \& Harris, B. (2018). Technology facilitated coercive control: Domestic violence and the competing roles of digital media platforms. Feminist Media Studies, 18(4), 609-625. doi:10.1080/14680777.2018.1447341

Dragiewicz, M., Harris, B., Woodlock, D., Salter, M., Easton, H., Lynch, A., ... Milne, L. (2019). Domestic violence and communication technology: Survivor experiences of intrusion, surveillance, and identity crime. Sydney, NSW: The Australian Communications Consumer Action Network (ACCAN).

Dunn, S., Lalonde, J., \& Bailey, J. (2017). Terms of silence: Addressing weaknesses in corporate and law enforcement responses to cyberviolence against girls. Girlhood Studies, 10(2), 80-96.

Finkelhor, D., Ormrod, R. K., Turner, H. A., \& Hamby, S. L. (2005). Measuring poly-victimization using the Juvenile Victimization Questionnaire. Child Abuse \& Neglect, 29(11), 1297-1312.

Flynn, A. (2019). 'Image-based abuse: The disturbing phenomenon of the "deep fake." Monash Lens, 12 March. Retrieved from https://lens.monash.edu/@politics-society/ 2019/03/12/1373665/image-based-abuse-deep-fake

Fraser, C., Olsen, E., Lee, K., Southworth, C., \& Tucker, S. (2010). The new age of stalking: Technological implications for stalking. Juvenile and Family Court Journal, 61(4), 39-55.

George, A., \& Harris, B. (2014). Landscapes of violence: Women surviving family violence in regional and rural Victoria. Centre for Rural and Regional Law and Justice, Deakin University. Retrieved from https:/www.deakin.edu.au/_data/ assets/pdf_file/0003/287040/Landscapes-of-Violence-online-pdf-version.pdf

Gerwitz-Meydan, A., Walsh, W., Wolak, J., \& Finkelhor, D. (2018). The complex experience of child pornography survivors. Child Abuse \& Neglect, 80, 238-248. doi:10.1016/j.chiabu.2018.03.031

Gillett, R. (2019). Everyday violence: Women's experiences of intimate intrusions on Tinder. Doctoral dissertation, Queensland University of Technology, Brisbane, QLD.

Green, A. (2019). Cucks, fags and useful idiots: The othering of dissenting white masculinities online. In K. Lumsden \& E. Harmer (Eds.), Online othering: Exploring digital violence and discrimination on the Web (pp. 65-90). Cham: Palgrave Macmillan.

Hall, P. (2019). Disability hate speech: Interrogating the online/offline distinction. In K. Lumsden \& E. Harmer (Eds.), Online othering: Exploring digital violence and discrimination on the Web (pp. 309-330). Cham: Palgrave Macmillan.

Hall, M., \& Hearn, J. (2017). Revenge pornography: Gender, sexuality and motivations. Abingdon: Routledge.

Harris, B. (2020). Technology, domestic and family violence: Perpetration, experiences and responses. Brisbane: QUT Centre for Justice. 


\section{Jane Bailey et al.}

Harris, B., \& Woodlock, D. (2018). Spaceless violence and advocacy: Technologyfacilitated abuse, stalking and service provision in regional, rural and remote Australia. Canberra, ACT: Australian Institute of Criminology.

Harris, B. A., \& Woodlock, D. (2019). Digital coercive control: Insights from two landmark domestic violence studies. British Journal of Criminology, 59(3), 530-550.

Henry, N., \& Flynn, A. (2019). Image-based sexual abuse: Online distribution channels and illicit communities of support. Violence Against Women, 25(16), $1932-1955$.

Henry, N., Flynn, A., \& Powell, A. (2018). Policing image-based sexual abuse: Stakeholder perspectives. Police Practice and Research: International Journal, 19(6), 565-581.

Henry, N., Flynn, A., \& Powell, A. (2019). Responding to revenge pornography: Prevalence, nature and impacts. Canberra, ACT: Australian Research Council.

Henry, N., Flynn, A., \& Powell, A. (2020). Technology-facilitated domestic and sexual violence: A review. Violence Against Women, 26(15-16), 1828-1854.

Henry, N., McGlynn, C., Flynn, A., Johnson, K., Powell, A., \& Scott, A. J. (2020). Image-based sexual abuse: A study on the causes and consequences of non-consensual nude or sexual imagery. London and New York, NY: Routledge.

Henry, N., \& Powell, A. (2015). Beyond the "sext": Technology-facilitated sexual violence and harassment against adult women. Australian and New Zealand Journal of Criminology, 48(1), 104-118.

Henry, N., Powell, A., \& Flynn, A. (2018). AI can now create fake porn, making revenge porn even more complicated. The Conversation, 28 February 2018. Retrieved from https://theconversation.com/ai-can-now-create-fake-porn-makingrevenge-porn-even-more-complicated-92267

Hinduja, S. (2018). Cultivating resilience to prevent bullying and cyberbullying. Cyberbullying Research Center. Retrieved from https://cyberbullying.org/cultivating-resilience-prevent-bullying-cyberbullying

Hinduja, S., \& Patchin, J. W. (2008). Cyberbullying: An exploratory analysis of factors related to offending and victimization. Deviant Behavior, 29(2), 129-156.

Jane, E. A. (2014). "Your a ugly, whorish, slut": Understanding e-bile. Feminist Media Studies, 14(4), 531-546.

Jane, E. (2017). Feminist digilante responses to a slut-shaming on Facebook. Social Media + Society. doi:10.1177/2056305117705996

Karayianni, E., Fanti, K. A., Diakidoy, I.-A., Hadjicharalambous, M.-Z., \& Katsimicha, E. (2017). Prevalence, contexts and correlates of child sexual abuse in Cyprus. Child Abuse \& Neglect, 66, 41-52. doi:10.1016/j.chiabu.2017.02.016

Kerrigan, N. (2019). Rural racism in the digital age. In K. Lumsden \& E. Harmer (Eds.), Online othering: Exploring digital violence and discrimination on the Web (pp. 259-286). Cham: Palgrave Macmillan.

Lenhart, A., Ybarra, M., \& Price-Feeney, M. (2016a). Nonconsensual image sharing: One in 25 Americans has been a victim of "revenge porn." New York, NY: Data \& Society Research Institute. Retrieved from https://datasociety.net/pubs/oh/ Nonconsensual_Image_Sharing_2016.pdf

Lenhart, A., Ybarra, M., Zickuhr, K., \& Price-Feeney, M. (2016b). Online harassment, digital abuse, and cyberstalking in America. New York, NY: Data \& Society Research Institute. Retrieved from https://www.datasociety.net/pubs/oh/Online_ Harassment_2016.pdf 
Lewis, R., Rowe, M., \& Clare, W. (2019). Online/offline continuities: Exploring misogyny and hate in online abuse of feminists. In K. Lumsden \& E. Harmer (Eds.), Online othering: Exploring digital violence and discrimination on the Web (pp. 121-143). Cham: Palgrave Macmillan.

Lumsden, K. (2019). "I want to kill you in front of your children" is not a threat. It's an expression of a desire: Discourses of online abuse, trolling and violence on r/MensRights. In K. Lumsden \& E. Harmer (Eds.), Online othering: Exploring digital violence and discrimination on the Web (pp. 91-117). Cham: Palgrave Macmillan.

Lumsden, K., \& Harmer, E. (Eds.) (2019). Online othering: Exploring digital violence and discrimination on the Web. Cham: Palgrave Macmillan.

Mandau, M. B. H. (2020). 'Directly in your face': A qualitative study on the sending and receiving of unsolicited 'dick pics' among young adults. Sexuality \& Culture, 24, 72-93. doi:10.1007/s12119-019-09626-2

Marganski, A., \& Melander, L. (2018). Intimate partner violence victimization in the cyber and real world: Examining the extent of cyber aggression experiences and its association with in-person dating violence. Journal of Interpersonal Violence, 33(7), 1071-1095.

McGlynn, C., Johnson, K., Rackley, E., Henry, N., Gavey, N., Powell, A., \& Flynn, A. (2020). "It's torture for the soul": The harms of image-based sexual abuse. Social \& Legal Studies, online first. doi:10.1177/0964663920947791

McGlynn, C., Rackley, E., Johnson, K., Henry, N., Flynn, A., Powell, A., ... Scott, A. J. (2019). Shattering lives and myths: A report on image-based sexual abuse. Durham: University of Durham. Retrieved from https://www.researchgate.net/ publication/339352950_Shattering_lives_and_myths_A_report_on_image-based_ sexual_abuse/citations\#fullTextFileContent

Megarry, J. (2014). Online incivility or sexual harassment? Conceptualising women's experiences in the digital age. Women's Studies International Journal, 47, 46-55.

Messing, J., Bagwell-Gray, M., Brown, M. L., Kappas, A., \& Durfee, A. (2020). Intersections of stalking and technology-based abuse: Emerging definitions, conceptualization, and measurement. Journal of Family Violence, 1-12.

Office of the eSafety Commissioner [OeSC]. (2017). Image-based abuse national survey: Summary report. Melbourne, VIC: OeSC. Retrieved from https://www.esafety. gov.au/sites/default/files/2019-07/Image-based-abuse-national-survey-summaryreport-2017.pdf

Office of the eSafety Commissioner [OeSC]. (2019a). eSafety for women from culturally and linguistically diverse backgrounds: Summary report. Melbourne, VIC: OeSC. Retrieved from https://www.esafety.gov.au/sites/default/files/2019-07/summaryreport-for-women-from-cald-backgrounds.pdf

Office of the eSafety Commissioner [OeSC]. (2019b). Understanding the attitudes and motivations of adults who engage in image-based abuse: Summary report. Melbourne, VIC: Social Research Centre. Retrieved from https://www.esafety.gov.au/ sites/default/files/2019-

Office of the eSafety Commissioner [OeSC]. (2019c). Online safety for Aboriginal and Torres Strait Islander women living in urban areas. Melbourne, VIC: Social Research Centre. Retrieved from https://www.esafety.gov.au/sites/default/files/ 2019-10/Online $\% 20$ safety $\% 20$ for $\% 20$ ATSI $\%$ 20women $\% 20$ living $\% 20$ in $\%$ 20urban $\%$ 20areas.pdf 
Office of the eSafety Commissioner [OeSC]. (2020). Online hate speech: Findings from Australia. New Zealand and Europe. Retrieved from https://www.esafety.gov.au/ sites/default/files/2020-01/Hate\%20speech-Report.pdf

Oswald, F., Lopes, A., Skoda, K., Hesse, C. L., \& Pederson, C. L. (2020). I'll show you mine so you'll show me yours: Motivations and personality variables in photographic exhibitionism. The Journal of Sex Research, 57(5), 597-609.

Palmater, P. (2016). Shining the light on the dark places: Addressing police racism and sexualized violence against Indigenous women and girls in the National Inquiry. Canadian Journal of Women and the Law, 28(2), 253-284.

Pavan, E. (2017). Internet intermediaries and online gender-based violence. In L. Vitis, \& M. Segrave (Eds.), Gender, technology and violence (pp. 62-78). London: Routledge.

Perry, B., \& Olsson, P. (2009). Cyberhate: The globalization of hate. Information and Communications Technology Law, 18(2), 185-199. doi:10.1080/13600830902814984

Pew Research Center. (2014). Online harassment. Retrieved from http://www. pewinternet.org/2014/10/22/online-harassment/

Powell, A., \& Henry, N. (2017). Sexual violence in a digital age. London: Palgrave Macmillan.

Powell, A., \& Henry, N. (2019). Technology-facilitated sexual violence victimization: Results from an online survey of Australian adults. Journal of Interpersonal Violence, 34(17), 3637-3665.

Powell, A., Henry, N., \& Flynn, A. (2018). Image-based sexual abuse. In W. S. DeKeseredy, \& M. Dragiewicz (Eds.), Routledge handbook of critical criminology (2nd ed., pp. 305-315). Abingdon and New York, NY: Routledge.

Powell, A., Henry, N., Flynn, A., \& Scott, A. J. (2019). Image-based sexual abuse: The extent, nature, and predictors of perpetration in a community sample of Australian residents. Computers in Human Behavior, 92, 393-402.

Powell, A., Scott, A. J., Henry, N., \& Flynn, A. (2020). Image-based sexual abuse: An international study of victims and perpetrators. Melbourne, VIC: RMIT University.

Quayle, E., \& Koukopoulos, N. (2018). Deterrence of online child sexual abuse and exploitation, policing. Journal of Policy Practice, 13(3), 345-362.

Rowse, J., Bolt, C., \& Gaya, S. (2020). Swipe right: The emergence of dating-app facilitated sexual assault. A descriptive retrospective audit of forensic examination caseload in an Australian metropolitan service. Forensic Science, Medicine and Pathology, 16, 71-77.

Ruvalcaba, Y., \& Eaton, A. A. (2019). Nonconsensual pornography among US adults: A sexual scripts framework on victimization, perpetration, and health correlates for women and men. Psychology of Violence, 10, 68-78. doi:10.1037/vio0000233

Salter, M. (2018). Child sexual abuse: Ethics and evidence. Child Sexual Abuse Review, 27(3), 165-170.

Schweppe, J. (2018). Abusive and offensive online communications: An Irish perspective. London: UK Law Commission. Retrieved from https://s3-eu-west-2.amazonaws.com/ lawcom-prod-storage-11jsxou24uy7q/uploads/2018/11/Ireland-J-Schweppe.pdf

Scrivens, R., \& Amarasingam, A. (2020). Haters gonna "like": Exploring Canadian far-right extremism on Facebook. In M. Littler \& B. Lee (Eds.), Digital extremisms: Readings in violence, radicalisation and extremism in the online space (pp. 63-89). Cham: Palgrave Macmillan. 
Sheikh, M. M. R. (2018). Technology mediated violence against women in Bangladesh: Evidence from contemporary literature. In S. Sapna \& S. Sharma (Eds.), Gender equality through mainstreaming: Proceedings of international conference on gender equality through the strategy of gender mainstreaming, Bengaluru (p. 198).

Smith, J. (2019). 'When I saw women being attacked it made me want to stand up and fight': Reporting, responding to, and resisting online misogyny. In K. Lumsden \& E. Harmer (Eds.), Online othering: Exploring digital violence and discrimination on the Web (pp. 287-308). Cham: Palgrave Macmillan.

Southern, R., \& Harmer, E. (2019). Othering political women: Online misogyny, racism and ableism towards women in public life. In K. Lumsden, \& E. Harmer (Eds.), Online othering: Exploring digital violence and discrimination on the Web (pp. 187-213). Cham: Palgrave Macmillan.

Tanczer, L., Lopez Neira, I., Parkin, S., Patel, T., \& George, D. (2018). Gender and IoT research report: The rise of the Internet of Things and implications for technology-facilitated abuse. London: STEaPP, PETRAS IoT Hub. Retrieved from https://www.ucl.ac.uk/research/domains/sites/research_domains/files/giotreport.pdf

Thomasen, K. (2018). Beyond airspace safety: A feminist perspective on drone privacy regulation. Canadian Journal of Law and Technology, 16(2), 307-338.

Vitis, L., \& Gilmour, F. (2017). Dick pics on blast: A woman's resistance to online sexual harassment using humour, art and Instagram. Crime, Media, Culture, 13(3), 335-355.

Weathers, M. R., \& Hopson, M. C. (2015). 'I define what hurts me': A co-cultural theoretical analysis of communication factors related to digital dating abuse. Howard Journal of Communications, 26(1), 95-113.

Wong, R. (2019). A guide for Canadian women experiencing technology-facilitated violence: Strategies for enhancing safety. Vancouver, BC: BC Society of Transition Houses. Retrieved from https://bcsth.ca/wp-content/uploads/2019/03/BCSTH-Aguide-for-Canadian-women-experiencing-technology-facilitated-violence-2019-1. pdf

Woodlock, D. (2017). The abuse of technology in domestic violence and stalking. Violence Against Women, 23(5), 584-602.

Ybarra, M., Price-Feeney, M., Lenhart, A., \& Zickuhr, K. (2017). Intimate partner digital abuse. Data \& Society Research Institute. Centre for Innovative Public Health Research. Retrieved from https://datasociety.net/pubs/oh/Intimate_ Partner_Digital_Abuse_2017.pdf 